\title{
Cellular and Molecular Damage by Ganaxolide on Phanerochaete Chrysosporium
}

\author{
Hongxia Xiong, Changbing Liu, Aijing Li, Yu Lin, and Wei Huang
}

\begin{abstract}
Galaxolide (1, 3, 4, 6, 7, 8-hexahydro-4, 6, 6, 7, 8, 8-hexamethyl-cyclopenta- $\gamma$-2-benzopyran, HHCB) is recognized as a novel contaminant in water and has potential adverse impacts on aquatic organisms. The toxic effect of HHCB on Phanerochaete chrysosporium was investigated by exposure of the fungus in nitrogen-limited culture medium to various concentrations of HHCB. The cultivation results showed that both the size and the quantity of the mycelial pellets of $P$. chrysosporium could be reduced when the concentration of HHCB was higher than $300 \mathrm{mg} / \mathrm{L}$. DNA damage of $P$. chrysosporium by HHCB was also detected. Comparing with that in the control, the percent polymorphism under different concentrations of HHCB increased, from $21.4 \%$ to $42.9 \%$. In addition, the result of UPGMA (un-weighted pair group method of arithmetic means) dendrogram showed that the Simple Matching Coefficient (SM) was decreased with an increase in the concentrations of HHCB. Thus, as an environmental pollutant, HHCB has the toxic effect on $P$. chrysosporium at both cellular and molecular level.
\end{abstract}

Index Terms-AFLP, Phanerochaete chrysosporium, HHCB, DNA damaging effects.

\section{INTRODUCTION}

Galaxolide (HHCB) belongs to the group of polycyclic musk fragrances and is widely used as perfuming agent in soaps, detergents and cosmetics [1]. The worldwide usage of HHCB has been estimated at approximately 6000 t every year [2]. After being applied for more than 50 years, the vast usage and incomplete removal in wastewater treatment plants have led to widespread existences of HHCB in the environment, the high concentrations of HHCB have been detected in sewage sludge (703.68 mg/kg) [3] and fish (1513 mg/kg) [4]. Once in the aquatic environment, HHCB can enter the food chain, being taken up by aquatic organisms. Following wastewater treatment, sewage sludge is digested, dewatered and then the resulting "biosolids" are commonly applied to agricultural land. HHCB in the sludge that have not been degraded during digestion are therefore introduced to the terrestrial ecosystem by entering the soil [5]. Thus, HHCB is increasingly found in water and soil where they can pose a toxicological risk to the environment.

The potential ecosystem risk of HHCB is apparent, especially considering its ubiquitous presence. Though

Manuscript received May 20, 2014; revised July 17, 2014. This work was financially supported by the National Natural Science Foundation (grant No. 21037002) and the National Science Foundation for Post-doctoral Scientists of China (B19040).

Hongxia Xiong, Changbing Liu, Aijing Li, Yu Lin, and Wei Huang are with the Tianjin Research Institute for Water Transport Engineering, Key Laboratory of Environmental Protection in Water transport Engineering, Ministry of Transport, Tianjin 3, China (e-mail: xiongxiongbao@126.com, \{632528078,86055991,681137438\}@qq.com,fenzhen1@163.com). concerns have been raised about the toxicity of $\mathrm{HHCB}$, the available data on the toxicology of HHCB is insufficient, mainly focusing on mammalian and aquatic toxicity [6]. Api and Ford [7] reported that 90-d oral feeding study with rats showed no observable adverse effect level (NOAEL) of 150 $\mathrm{mg} / \mathrm{kg}$ HHCB. Similar studies on HHCB toxicity have also been reported on algae, crustacean, mussels and fishes [8][10].

In the past 20 years, white rot fungus has been investigated to develop biotechnology for the degradation of broad-spectrum, refractory organic pollutants in the environment based on their lignin degrading enzymes (such as Lip, MnP, and Lac). In recent years, many researchers have indicated that white rot fungi are promising microorganisms in wastewater treatment. The model white rot fungus $P$. chrysosporium is the most investigated species. At present, the researches on $P$. chrysosporium degrading the pollutants are focus on the enzymes used to degrade organic pollutants, mechanism in degrading process and the optimum condition of degrading process [11]. However, the research on DNA damage effects of $P$. chrysosporium caused by organic pollutants is rarely available.

The AFLP (amplified fragment length polymorphism) method as a new molecular markers technology is based on amplifying DNA fragments by PCR [12] and it can distinguish the slight differences of DNA fragments [13]. The damaging effect of pollutants to plants, algae and fungi with AFLP analysis was reported by previous researches [14]-[15], and it could effectively reflect DNA polymorphisms. Therefore, the AFLP technology makes it is possible to analyze the DNA damage on $P$. chrysosporium by HHCB.

The objective of this study is to evaluate the relationships between the concentrations of HHCB and DNA damaging effects by AFLP analysis and the UPGMA dendrogram.

\section{MATERIALS AND METHODS}

P. chrysosporium was purchased from the China Center of Industrial Culture Collection (Beijing, China).

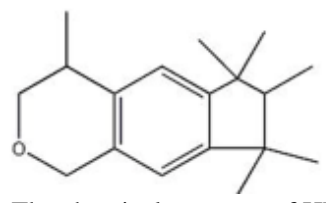

Fig. 1. The chemical structure of HHCB.

1, 3, 4, 6, 7, 8-Hexahydro-4, 6, 6, 7, 8, 8-hexamethyl-cyclopenta- $\gamma$-2-benzopyran (HHCB, see Fig. 1) was purchased from Tianjin Zhongkejian Chemical Co., Ltd. Biochemical reagents, the adapters, and primers were 
purchased from the Shanghai Biocolors Biotechnology Company (Shanghai China). All other used chemicals were of analytical grade.

\section{A. Microorganism and Culture Conditions}

$P$. chrysosporium strain CICC 40719 was maintained at $38^{\circ} \mathrm{C}$ on potato dextrose agar (PDA) plates and cultured for 5 days at $37^{\circ} \mathrm{C}$. P. chrysosporium spores on the plate were scraped into sterile water to form a spore suspension $(1 \times 106$ spores $/ \mathrm{mL}$ ). Adding $200 \mathrm{~mL}$ liquor culture into a $500 \mathrm{~mL}$ flask, incubating spores suspension $(1 \times 106$ spores $/ \mathrm{mL})$ in the flask, culturing at $37^{\circ} \mathrm{C}$, shaking at $150 \mathrm{rpm}$, adjusting the $\mathrm{pH}$ value of liquor culture to 4.8 with acetic acid-sodium acetate buffer $(10 \mathrm{mM} / \mathrm{L})$. All above were conducted aseptically. After shaking the culture for 6 days, four different concentrations of HHCB were added into the flask and then continuously cultured for 10 days.

$P$. chrysosporium as a biological engineering fungi, it contains all three enzymes and is therefore able to degrade or mineralize several organic pollutants, including HHCB. In addition, there is a certain amount of mycelial pellets of $P$. chrysosporium in cultivation liquid and HHCB can be absorbed easily and bounded firmly by mycelial pellets. Targeting growth and physiological characteristics of $P$. chrysosporium, chemical characteristics of $\mathrm{HHCB}$ and preliminary experiment, there were five HHCB treatments which included no HHCB (control), and 100, 200, 300, and $400 \mathrm{mg} / \mathrm{L}$ respectively. The collected mycelia pellets, after immersing and washing with aseptic water, were frozen in liquid nitrogen and stored at $-80^{\circ} \mathrm{C}$ until analysis.

\section{B. AFLP Methodology}

AFLP-PCR was performed as described by Keygene [12] with minor modifications. The adapter sequences, pre-selective amplification primers and selective primers are listed in Table I. $200 \mathrm{ng}$ of DNA were used for each reaction. DNA was digested $(3 \mathrm{~h})$ with EcoR I and Mse I (both entzymes from MBI Fermentas, Germany). Following heat inactivation of the restriction endonucleases, the restricted genomic DNA fragments were ligated (with T4 DNA-ligase) to EcoR I and Mse I adapters at $16^{\circ} \mathrm{C}$ overnight.

Digest-ligated DNA fragments were diluted fivefold to be used as templates of the pre-amplification reaction.

TABLE I: SEQUENCES OF OLIGONUCLEOTIDE ADAPTORS AND PRIMERS USED IN THE AFLP ANALYSIS

\begin{tabular}{|c|c|}
\hline Adapters/primers & Nucleotide sequences \\
\hline \multirow[t]{2}{*}{ EcoR I Adapters } & 5'- CTC GTA GAC TGC GTA CC- 3' \\
\hline & 5'- AAT TGG TAC GCA GTC TAC- 3' \\
\hline \multirow[t]{2}{*}{ Mse I Adapters } & 5'- GAC GAT GAG TCC TGA G- 3' \\
\hline & 5'- TAC TCA GGA CTC AT- 3' \\
\hline EcoR I ppa* & 5'- GAC TGC GTA CCA ATT CA- 3' \\
\hline Mse I ppa & 5'- GAT GAG TCC TGA GTA A C- 3' \\
\hline EcoR I pps** & 5’- GAC TGC GTA CCA ATT CACC- 3' \\
\hline Mse I pps & 5'- GAT GAG TCC TGA GTA ACA C- 3' \\
\hline
\end{tabular}

*Primers of preamplification.

*** Primers of selective amplification.

The $25 \mu$ amplification mixture contained 10×PCR buffer (with $1.5 \mathrm{mM} \mathrm{MgCl}_{2}$ ), $2 \mathrm{mM}$ of each dNTP, $10 \mathrm{pM}$ of EcoR I and Mse I pre-amplification primer, and 1.0 unit of Taq polymerase (Takara Biotechnology Company, Japan). After 2 min at $94^{\circ} \mathrm{C}$, amplification was carried out for 30 cycles of denaturation $\left(30 \mathrm{~s}\right.$ at $\left.94^{\circ} \mathrm{C}\right)$, annealing $\left(30 \mathrm{~s}\right.$ at $\left.56^{\circ} \mathrm{C}\right)$ and extension $\left(80 \mathrm{~s}\right.$ at $\left.72^{\circ} \mathrm{C}\right)$. After a final extension step $(5 \mathrm{~min}$ at $72^{\circ} \mathrm{C}$ ) the pre-amplifictaion product was diluted 20 times with double-distilled water and used as templates of the selective amplifications. The selective amplification mixture (20 $\mu$, final volume) contained $2 \mu$ l of diluted pre-amplification PCR product, $10 \mathrm{pM}$ of EcoR I and Mse I selective primers, 1.0 unit of Taq polymerase, $0.2 \mathrm{mM}$ of each dNTP, $1.5 \mathrm{mM} \mathrm{MgCl} 2$, and $10 \times$ PCR buffer. After 2 min at $94^{\circ} \mathrm{C}$, amplification took place for 36 cycles under the following conditions: denaturation for $30 \mathrm{~s}$ at $94^{\circ} \mathrm{C}$; annealing for $30 \mathrm{~s}$ at $65^{\circ} \mathrm{C}$ and extension for $80 \mathrm{~s}$ at $72^{\circ} \mathrm{C}$ for the first cycle, followed by lowering of the temperature $\left(0.7^{\circ} \mathrm{C}\right)$ in the next 12 cycles, then at $55^{\circ} \mathrm{C}$ for the remaining 23 cycles; extension for $80 \mathrm{~s}$ at $72^{\circ} \mathrm{C}$. Selective amplifications products were loaded onto a $4 \%$ denaturing polyacrylamide gel and electrophoresed in TBE buffer for $3 \mathrm{~h}$ at $80 \mathrm{~W}$. Fragment data were collected using SmartView software.

\section{Data Analysis}

Polymorphic bands of the AFLP fingerprinting were scored by visual inspection of the resulting autoradiograms. For statistical analysis, each AFLP band detected after electrophoresis of the DNA amplification products was scored as a binary character for its absence (1) or presence (0). Only reproducible bands were used to calculate Simple Matching Coefficient (SM). A dendrogram was constructed based on the similarity matrix by UPGMA (un-weighted pair group method of arithmetic means), using the MVSP program (version 3.1). Dendrogram is a possible graphical representation of AFLP data obtained. A dendrogram consists of many U-shaped lines connecting objects in a hierarchical tree; the height of each $U$ represents the distance between the two objects being connected and the differences between each other. In our analysis the dendrogram showed the relationship between treated samples in comparison with control treatments. This statistical analysis allows the DNA damage induced by different concentrations of HHCB to be quantified.

In addition, for each concentration of the HHCB, a percentage of polymorphism (P (\%)) was computed as: $\mathrm{P}(\%)$ $=($ number polymorphic bands/total detected bands $) \times 100$.

\section{RESUlts}

\section{A. Growth of P. Chrysosporium in the Shake Flask Culture}

The growth of $P$. chrysosporium in nitrogen-limited medium of different concentrations of HHCB was shown in Fig. 2. The growth of $P$. chrysosporium showed relatively large difference with different concentrations of HHCB (see Fig. 2).

In control group (No. 1), the oscillation condition has effect on the growth of $P$. chrysosporium by shear stress, and there were many spines on the surface of the mycelial pellets, and the structure was tight (Fig. 2a). When the concentrations of HHCB reached to $100 \mathrm{mg} / \mathrm{L}$ (No. 2), the quantity and the size of the mycelial pellets were kept almost the same with 
the control group. In addition, the spines of this group were smoother, and the structure was slightly looser than the control group. The results showed that $100 \mathrm{mg} / \mathrm{L} \mathrm{HHCB}$ did not affect the growth of $P$. chrysosporium, but the structure and function were changed partly (Fig. 2b). However, as the concentration of the HHCB was increased to $300 \mathrm{mg} / \mathrm{L}$, the quantity of the mycelial pellets reduced, but the size of the mycelial pellets had little differences compared with 200 $\mathrm{mg} / \mathrm{L}$, meantime, the structure of the mycelial pellets was looser and the spines disappeared compared with the control group. This meant that when the concentrations of HHCB reached $300 \mathrm{mg} / \mathrm{L}$, there were some influence on the growth and the outer features of $P$. chrysosporium (Fig. 2c, 2d), but had less influence on the function. From the Fig. 2e, we can obtain that the quantity of the mycelial pellets decreased significantly, the size of the mycelial pellets was significantly smaller, the spines disappeared comparing with the control group, and the mycelial pellets easily broken. This meant that there had a strong injury on the growth of $P$. chrysosporium when the concentrations of HHCB were increased to 400 $\mathrm{mg} / \mathrm{L}$.

The growth of $P$. chrysosporium in the shake flask culture showed that the quantity and the size of the mycelial pellets were related to the concentrations of HHCB. When the concentration of $\mathrm{HHCB}$ reached to $400 \mathrm{mg} / \mathrm{L}$, there would be a great influence on the growth and the function of $P$. chrysosporium (Fig. 2e). Therefore, the higher concentration of HHCB has noticeable effects on the growth of $P$. chrysosporium in this study.

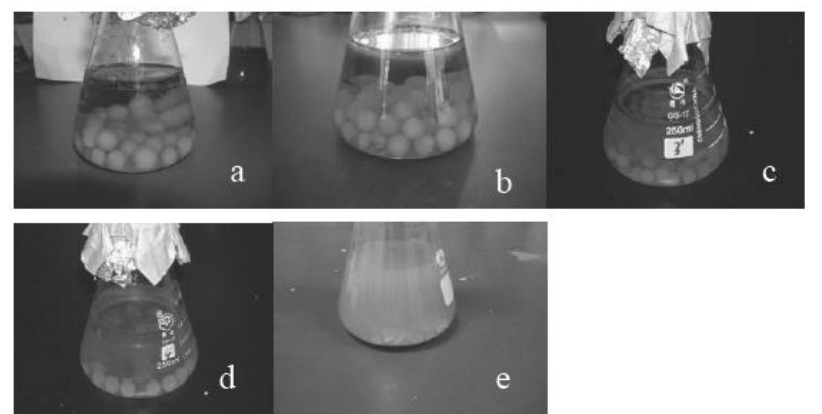

Fig. 2. Growth of P. chrysosporium in the shake flask culture after 10 days; (a) the mycelial pellets in the control group; (b) the mycelial pellets in the $100 \mathrm{mg} / \mathrm{L} \mathrm{HHCB}$; (c) the mycelial pellets in the $200 \mathrm{mg} / \mathrm{L} \mathrm{HHCB}$; (d) the mycelial pellets in the $300 \mathrm{mg} / \mathrm{L} \mathrm{HHCB}$; (e) the mycelial pellets in the 400 $\mathrm{mg} / \mathrm{L} \mathrm{HHCB}$.

\section{B. Damage Effects of the HHCB on DNA of P. Chrysosporium}

With the aim of verifying the genotoxic effect of the HHCB and quantifying DNA damage, AFLP analysis was used in DNA extracted from $P$. chrysosporium treated with different concentrations of HHCB. Eight different primer pairs were used for AFLP analysis. A representative example of the results obtained by the AFLP analysis was shown in Fig. 3, and the number of total, polymorphic bands and percentage of polymorphism of the primer E-ACC/M-CTC were given in Table II.

The AFLP fingerprinting of $P$. chrysosporium under different concentrations of HHCB was shown in Fig. 3. Fig. 3 showed that the bands that could be used were comparatively rich and the special DNA fragments were significant, meanwhile, the repeatability was good.
Table II showed that, compared with control group (No. 1), the number of total and polymorphic bands was increasing when the concentration of HHCB was elevated. The percentage of polymorphism was increasing from $21.40 \%$ to $42.90 \%$. The results in Table II marked that the damage of $100 \mathrm{mg} / \mathrm{L}$ (No. 2) to $P$. chrysosporium was slightest, and the percentage of polymorphism of $100 \mathrm{mg} / \mathrm{L}$ compared with the blank control group was kept at $21.40 \%$. Compared with control group, the percentage of polymorphism of No. 3 and No. 4 was from $32.20 \%$ to $35.90 \%$ that they were higher than No. 2. Compared with the blank control group, the percentage of polymorphism of $400 \mathrm{mg} / \mathrm{L}$ was $42.90 \%$, this meant that the damage of $400 \mathrm{mg} / \mathrm{L}$ to $P$. chrysosporium was worst. These results showed that the damage of HHCB to $P$. chrysosporium was significant.

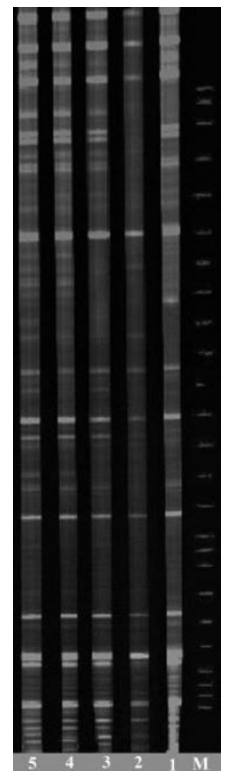

Fig. 3. Fingerprinting of AFLP with primer pair of E-ACC/M-CTC; (1) the bands in the control group; (2) the bands in the $100 \mathrm{mg} / \mathrm{L} \mathrm{HHCB}$; (3) the bands in the $200 \mathrm{mg} / \mathrm{L} \mathrm{HHCB}$; (4) the bands in the $300 \mathrm{mg} / \mathrm{L} \mathrm{HHCB}$; and (5) the bands in the $400 \mathrm{mg} / \mathrm{L} \mathrm{HHCB}$.

TABLE II: STATISTIC OF THE AMPLIFICATION GENERATED By PRIMER PAIR OF E-ACC/M-CTC

\begin{tabular}{cccc}
\hline Sample & $\begin{array}{c}\text { No. of } \\
\text { total bands }\end{array}$ & $\begin{array}{c}\text { No. of } \\
\text { polymorphic bands }\end{array}$ & $\%$ of polymorphism \\
\hline No. 1 & 36 & 0 & 0 \\
No. 2 & 28 & 6 & $21.40 \%$ \\
No. 3 & 31 & 10 & $32.20 \%$ \\
No. 4 & 39 & 17 & $35.90 \%$ \\
No. 5 & 42 & 18 & $42.90 \%$ \\
\hline
\end{tabular}

P. chrysosporium exposed to different concentrations of HHCB shows a significant degree of polymorphism if compared to the control treatment, the genotoxic effect was evident in the higher concentration of HHCB. However, the DNA polymorphism of $400 \mathrm{mg} / \mathrm{L}$ was higher than the other groups, which indicating that highest HHCB concentration effects on DNA were pronounced at this time.

Based on the data of similarity matrix produced by measuring the proportion of shared bands between the control treatment and different concentrations of HHCB, the UPGMA dendrogram of $P$. chrysosporium are was presented in Fig. 4.

A correlation between the polymorphic bands and the increasing $\mathrm{HHCB}$ was observed, as shown in the 
dendrogram. The SM similarity index among accessions varies from 0.75 (high genomic similarity with the control) to 0.60. Fig. 4 showed that the DNA similarity between the No. 2 and No. 1 was the best. The No. 3 and No. 4 showed descending trend. The DNA similarity of $P$. chrysosporium between the $400 \mathrm{mg} / \mathrm{L}$ and the control was the worst in this study. And the dendrogram result was consistent with cultivation results. Based on the UPGMA dendrogram, we determined that $P$. chrysosporium exposured to low concentration of HHCB did not show a significant degree of DNA polymorphism in comparison to the control treatment. Significant levels of genomic modification were detected in the $P$. chrysosporium treated with higher concentrations of $\mathrm{HHCB}$, and a greater genotoxic effect was revealed at the highest concentration.

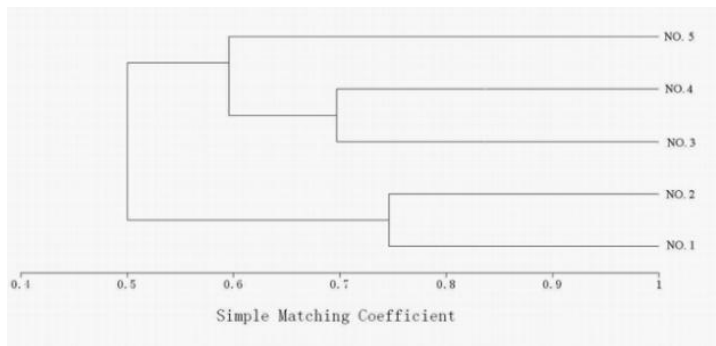

Fig. 4. UPGMA dendrogram of P. chrysosporium using MVSP (Version 3.1) program.

\section{DISCUSSION}

Due to the continuous input to the environment in high quantity, the residual concentration of HHCB is increasing. Meanwhile, the substance is hardly biodegradable, and is lipohilic and accumulated by organisms and is gradually shows ecological toxicity to the microorganisms, plants, animals, aquatic organisms and soil organisms and even potential ecological risk to human beings in prolonged tests. Therefore, the HHCB was included in this article.

Some evidences indicated that reactive oxygen species (ROS)-induced cellular oxidative injury of Eisenia fetida was one of the main toxic effect of HHCB, superoxide dismutase (SOD) and catalase (CAT) were both up-regulated at low exposure dose during $48 \mathrm{~h}$ test period, and down-regulation after $48 \mathrm{~h}$ exposure to high dose HHCB [16]. Our work showed that HHCB has certain oxidative stress on $P$. chrysosporium, and then influences the structure of $P$. chrysosporium. HHCB is hardly biodegradable and accumulated by organisms. $P$. chrysosporium or its oxidative enzymes can reduce the concentration of HHCB either by adsorption of HHCB on fungal mycelium or by oxidative degradation of HHCB molecule. So our experimental concentration of HHCB was higher than the concentration in the environment. Based on the preliminary experiment, we set four concentration gradients: 100, 200, 300, and 400 $\mathrm{mg} / \mathrm{L}$.

In the case of $\mathrm{HHCB}$, a strong growth inhibition effect was observed at $200 \mathrm{mg} / \mathrm{L}$, while at $100 \mathrm{mg} / \mathrm{L}$, no significant effect was observed. Comparing with the control treatment, HHCB has decreased both the size and the quantity of the mycelial pellets of $P$. chrysosporium when the concentration of HHCB over $300 \mathrm{mg} / \mathrm{L}$. This result was consistent with earlier reports which used other pollutants. It meant that
HHCB as an environmental pollutant may have some ecotoxicity on environmental organism.

DNA is considered to be the most important bio-macromolecule and target molecule responsible for all biological effects. Many kinds of damage can be induced by pollutants, such as base damage, single strand break (SSB), double strand break (DSB) and crosslink of DNA and protein. The primary mechanism of mutagenesis is through miscoding induced by the mutagen-DNA adducts.

The effects of HHCB on DNA of $P$. chrysosporium was also observed in this study, the percent polymorphism under different concentrations of $\mathrm{HHCB}$ were from $21.4 \%$ to $42.9 \%$, and the DNA similarity were decreasing, which meant that the DNA damage was increased with the increasing concentrations of HHCB. Basing on the analysis of AFLP profiles, we inferred that polymorphisms induced by HHCB was due to mutations in the AFLP enzymes restriction sequences or to random breaks in DNA. DNA damage and in particular random breaks in DNA could be induced from oxygen radicals formed during the biotransformation of HHCB [17]. Generally, DNA is subject to continuous oxidative damage from oxygen radicals generated during normal cellular metabolism and unrepaired DNA damage can lead to mutation [18]. We supposed that HHCB increased the rate of damage above background levels and thus enlarged the potential for unrepaired lesions to become permanent mutations. Our hypothesis was supported by an investigation conducted previously on rat liver [19] and on human cells.

Oxidative damage seems to be a major mechanism involved in DNA toxicity induced by organic and inorganic pollutants [19] and our test conducted with HHCB supports this consideration. HHCB was able to produce DNA damages in $P$. chrysosporium cells probably by some of the products of DNA oxidative damage such as modified bases, primarily 8-oxoguanine, abasic sites, base adducts of carbon-centred radicals and single or double strand breaks in the phospho-sugar back-bone of DNA [20]. These mutations were observed in our AFLP analysis and data suggested that HHCB was a mutagenic agent, especially at high concentrations.

\section{CONCLUSIONS}

From the results obtained in this study, it can be concluded that HHCB as an environmental pollutant may have some physiological ecotoxicity on environmental organism. But in this study, the concentration of HHCB used as treatment was much higher than the background. So, HHCB could not affect the degradation effect of $P$. chrysosporium in wastewater treatment.

\section{ACKNOWLEDGMENT}

The authors thank the professor Qixing Zhou for his help in the design and research.

\section{REFERENCES}

[1] S. Tanabe, "Synthetic musks-arising new environmental menace," Marine Pollution Bulletin, vol. 50, no. 10, pp. 1025-1026, Oct. 2005.

[2] G. G. Rimkus, "Polycyclic musk fragrances in the aquatic environment," Toxicology Letters, vol. 111, no. 1-2, pp. 37-56, Dec. 1999. 
[3] X. Y. Zeng, G. Y. Sheng, Y. Xiong, and J. M. Fu, "Determination of polycyclic musks in sewage sludge from Guangdong, China using GC EI-MS," Chemosphere, vol. 60, no. 6, pp. 817-823, Aug. 2005.

[4] H. Fromme, T. Otto, and K. Pilz, "Polycylic musk fragrances in different environmental compartments in Berlin (Germany)," Water Research, vol. 35, no. 1, pp. 121-128, Jan. 2001.

[5] A. M. DiFrancesco, P. C. Chiu, L. J. Standley, H. E. Allen, and D. T. Salvito, "Dissipation of fragrance materials in sludge-amended soils," Environmental Science \& Technology, vol. 38, no. 1, pp. 194-201, Jan. 2000.

[6] M. S. Christian, R. M. Parker, A. M. Hoberman, R. M. Diener, and A. M. Api, "Developmental toxicity studies of four fragrances in rats," Toxicology Letters, vol. 111, no. 1-2, pp. 169-174, Dec. 1999.

[7] A. M. Api and R. A. Ford, "Evaluation of the oral subchronic toxicity of $\mathrm{HHCB}(1,3,4,6,7,8$-hexahydro-4, 6, 6, 7, 8, 8-hexamethylcyclopenta-gamma-2-benzopyran) in the rat," Toxicology Letters, vol. 111, no. 1-2, pp. 143-149, Dec. 1999.

[8] G. Carlsson and L. Norrgren, "Synthetic musk toxicity to early life stages of zebrafish (Danio rerio)," Archives Environmental Contamination and Toxicology, vol. 46, no. 1, pp. 102-105, Jan. 2004.

[9] M. P. Gooding, T. J. Newton, M. R. Bartsch, and K. C. Hornbuckle, "Toxicity of synthetic musks to early life stages of the freshwater mussel Lampsilis cardium," Archives Environmental Contamination and Toxicology, vol. 51, no. 4, pp. 549-558, Nov. 2006.

[10] L. Wollenberger, M. Breitholtz, K. O. Kusk, and B. E. Bengtsson, "Inhibition of larval development of the marine copepod Acartia tonsa by four synthetic musk substances," The Science of the Total Environment, vol. 305, no. 1-3, pp. 53-64, Apr. 2003.

[11] K. L. Sublette, E. V. Ganapathy, and S. Schwartz, "Degradation of munition wastes by Phanerochaete chrysosporium," Applied Biochemistry and Biotechnology, vol. 34-35, no. 1, pp. 709-723, Feb. 1992.

[12] P. Vos, L. Hogers, M. Bleeker, M. Reijans et al., "AFLP: A new technique for DNA fingerprinting," Nucleic Acids Research, vol. 23, no. 21, pp. 4407-4414, Nov. 1995.

[13] H. M. Meudt and A. C. Clarke, "Almost forgotten or latest practice? AFLP applications, analyses and advances," Trends in Plant Science, vol. 12, no. 3, pp. 106-117, Feb. 2007.

[14] M. Labra, T. Di Fabio, F. Grassi, S. M. Regondi, M. Bracale, C. Vannini, and E. Agradi, "AFLP analysis as biomarker of exposure to organic and inorganic genotoxic substances in plants," Chemosphere, vol. 52, no. 7, pp. 1183-1188, Aug. 2003.

[15] M. Labra, F. De Mattia, M. Bernasconi, D. Bertacchi, F. Grassi, I. Bruni, and S. Citterio, "The combined toxic and genotoxic effects of chromium and volatile organic contaminants to Pseudokirchneriella subcapitata," Water, Air, and Soil Pollution, vol. 213, no. 1-4, pp. 57-70, Nov. 2010.

[16] C. Chen, Q. X. Zhou, S. Liu, and Z. M. Xiu, "Acute toxicity, biochemical and gene expression responses of the earthworm Eisenia fetida exposed to polycyclic musks," Chemosphere, vol. 83, no. 8, pp. 1147-1154, Feb. 2011

[17] S. A. Walles, "Induction of single-strand breaks in DNA of mice by trichloroethylene and tetrachloroethylene," Toxicology Letters, vol. 31 , no. 1, pp. 31-35, Apr. 1986
[18] M. Labra, M. Bernasconi, F. Grassi, F. De Mattia, S. Sgorbati, R. Airoldi, and S. Citterio, "Toxic and genotoxic effect of potassium dichromate in Pseudokirchneriella subcapitata detected by microscopi and AFLP analysis," Aquatic Botany, vol. 86, no. 3, pp. 229-235, Apr. 2007.

[19] M. Toraason, J. Clark, D. Dankovic, P. Mathias, S. Skaggs, C. Walker, and D. Werren, "Oxidative stress and DNA damage in fischer rats following acute exposure to trichloroethylene or perchloroethylene," Toxicology, vol. 138, no. 1, pp. 43-53, Oct. 1999.

[20] S. S. Wise, A. L. Holmes, and J. P. Wise, "Hexavalent chromium-induced DNA damage and repair mechanisms," Reviews on Environmental Health, vol. 23, no. 1, pp. 39-57, Jan.-Mar. 2008.

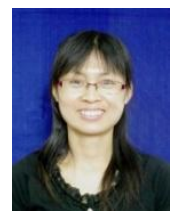

Hongxia Xiong received her bachelor degree in biology engineer in Shanxi University, Taiyuan, China in 2003 and $\mathrm{Ph} . \mathrm{D}$. degree in microbiology in Institute of Applied Ecology, Chinese Academy of Science in 2009, Shenyang, China. Her current interests include ecological remediation, environmental protection and ecotoxicology.

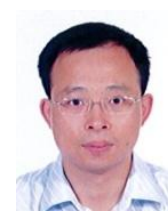

Changbing Liu received his bachelor degree in environment engineering in Harbin University of Civil Engineering and Architecture in 1993, Harbin, China. His current interests include environmental protection and environment engineering.

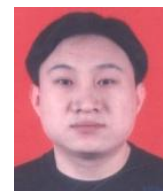

Aijing $\mathbf{L i}$ received his bachelor degree in environmental Sciences in Hebei University of Science and Technilogy in 2003, Shijiazhuang, China. His current interest is traffic environmental protection.

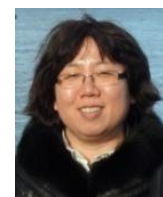

Yu Lin received her bachelor degree in applied chemistry in Shanghai Jiao Tong University in 1995, Shanghai, China. Her current interest is traffic environmental protection.

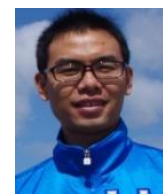

Wei Huang received his bachelor degree in biology engineer in Shanxi University in 2003, Taiyuan, China, and Ph.D. degree in ecology in Institute of Applied Ecology, Chinese Academy of Science in 2008, Shenyang, China. His current interests include ecological remediation and environmental protection. 